\title{
Actores errantes de oitocentos
}

\section{Guilherme Filipe}

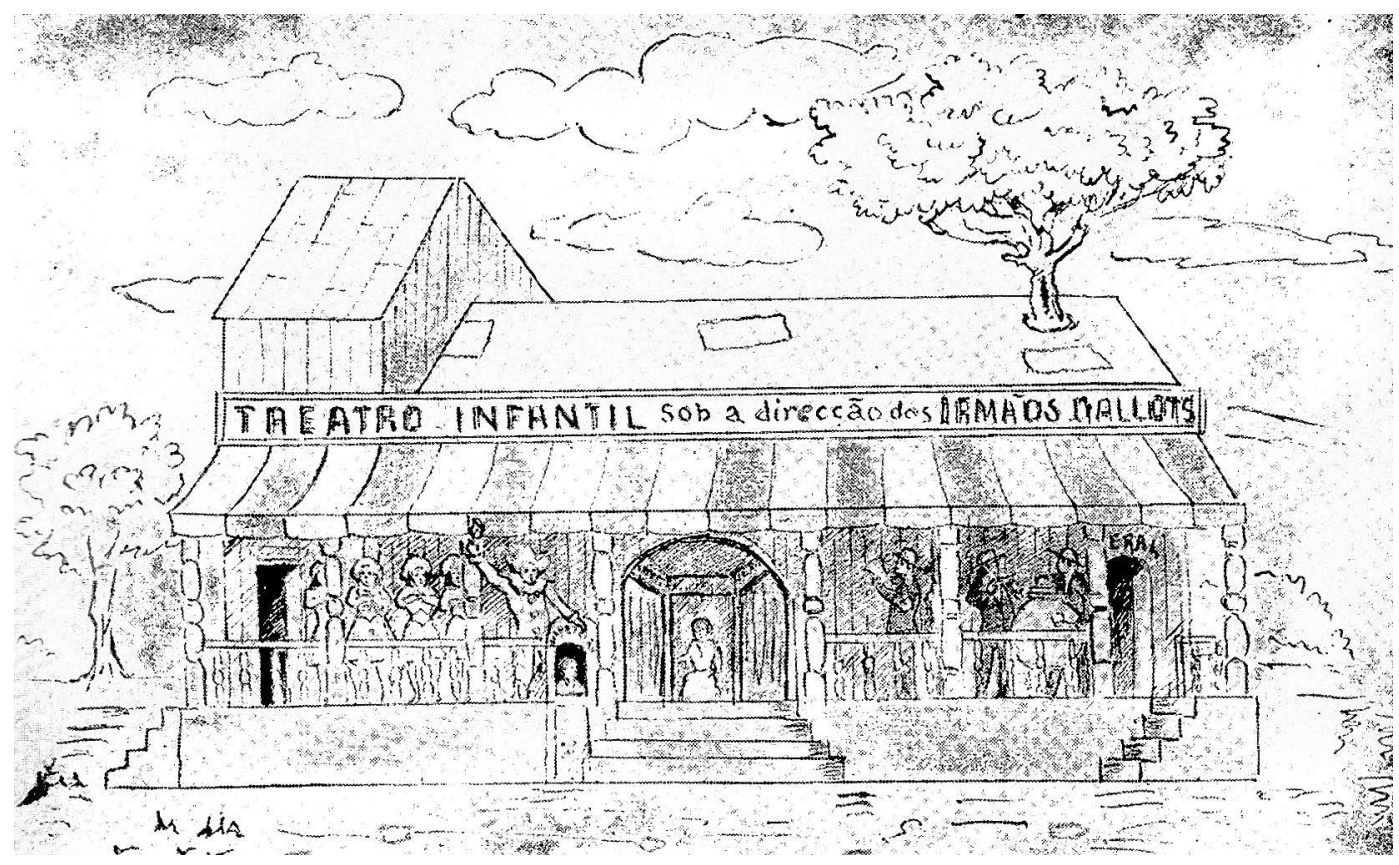

Teatro Infantil - Teatro de Feira - sob a direcção dos Irmãos Dallot - montado nas feiras das Amoreira e Belém na década de 1870 (Revista $A B C$ 1928-08-19, p.15)

\section{A vida errante de companhias ambulantes}

Esta é uma existência que se documenta nos arquivos do Ministério do Reino (MR) ou dos Governos Civis, organismo que assumiu a responsabilidade do licenciamento dos espectáculos após a reforma administrativa de 1869. Com contornos literários, D. João da Câmara (1902: 5-6) fezIhes o retrato em "A Farândola", com pinceladas evocadoras de EI Viaje Entretenido, de Rojas (1572 - 1635), ou do Roman Comique, de Scarron (1610 - 1680) ou das pinturas de Karel Dujardin (1626 - 1678). Calcorreando as estradas, carregando os pertences, "a transferência para qualquer terra era uma perfeita caravana composta de dez carros de bois ou carroças, cheias de cenário, mobiliário, (...) a cavalo, por montes e vales, desde Chaves a Bragança. Toda a companhia montada em burros e cavalos dava a impressão d'uma troupe de ciganos" (Cabral 1923: 35-36). 0 desenvolvimento da via-férrea amenizou as dificuldades de transporte, mas ampliou o seu campo de actuação, definindo com mais acuidade uma rota dos palcos. E quando o animatógrafo, entrou, pela novidade, nos hábitos das populações, e, pela receita, nos bolsos dos empresários dos teatros locais, às companhias de província não Ihes restou outra alternativa senão retornarem à construção dos seus teatros-barraca, os chalets, de madeira e tela, da tradição feirante, como forma sobrevivência.

Apesar da instabilidade social provocada pelas invasões francesas ou pelas guerras liberais, o território português foi visitado, ao longo do século XIX, por grupos de profissionais, nacionais e estrangeiros, que colmataram a necessidade da diversão popular. Companhias dramáticas, líricas (de Zarzuela), circenses (ginastas e acrobatas), circos de cavalinhos com espectáculos de pantomima, teatros de marionetas, em palcos públicos ou nos recintos de feira, extasiaram olhos ávidos de emoções. A par das corridas de touros, o público entusiasmou-se com a exposição de animais domésticos e amestrados, com as feras enjauladas, em jardins zoológicos ambulantes. Propostas de outras realidades distantes, apelos ao exotismo de "ratas indianas", num vislumbre de sensações piturescas económicas, acedendo a barracas de ilusões ópticas - panoramas, cicloramas, cosmoramas -, filhas de Daguerre,

proporcionavam viagens inimagináveis. A ciência dos jogos da fisica e química causou tanto espanto popular quanto as aberrações, gente que exibia publicamente as suas deformidades para não ter que mendigar o sustento diário nas ruas.

A ideia de actividade cultural centrada em Lisboa cai pele base quando confrontamos os pedidos de licenciamento das companhias itinerantes. Em 1861, chega ao Ministério do Reino o requerimento de "Maria Augusta Bessa Lopes, directora da denominada Companhia Lopes", apensado do parecer do Governador Civil de Beja, pedindo "licença por um ano para dar representações em qualquer Teatro do Reino"1. Uma das muitas companhias de declamação que percorreram as provincias, viajaram até às ilhas, levando o Teatro a uma população rural. A legislação de 1860 define
A 26 de Junho de 1861 Arquivo Nacional Torre do Tombo - ANTT / Ministério do Reino - MR) / Direcção Geral da Instrução Pública - DGIP, L. 20, n. 598)

Guilherme Filipe

é actor e encenador, formado pela Escola Superior de Teatro e Cinema, e fundador do Grupo Persona. Integra como investigador o Centro de Estudos de Teatro, é Mestre em Estudos de Teatro pela Faculdade de Letras da Universidade de Lisboa com uma dissertação sobre a Companhia Rafael de Oliveira e prepara actualmente 0 seu doutoramento na mesma área científica. 
Cartaz de

0 Marquez de Pombol

pela Sociedade Dramática

Empresária, companhia

do Teatro Chalet

Dramático, de

Constantino de Matos

(finais do séc. XIX).
2 ANT, Governo Civil de Lisboa, copiador n. $75 / 67$ 88/72, NT 184, reg. ${ }^{\circ} .{ }^{\circ} 56$, de 01.07 .1868

${ }^{3}$ ANTT, Ministério do Reino, Direcção Geral de Instrução Pública, L. 22 n. ${ }^{\circ} 1036$

${ }^{4}$ Governo Civil de Lisboa (ANT), copiador n. $75 / 67-88 / 72$, NT 184 reg. ${ }^{\circ}$. 39 , de 28.05.1868 que a Direcção-geral de Instrução Pública superintenda os teatros, nomeie delegados provinciais e execute um censo teatral: cadastram-se teatros públicos e particulares e os artistas que neles representam, fazem-se estatísticas, organizam-se mapas de peças, de exploração teatral e de rendimento, sem excepções. 0 expediente teatral aumenta e, ainda que haja fugas ao licenciamento, constatam-se companhias de provincia com actividade duradoura: as de André Augusto Xavier de Macedo, de Francisco Fernandes, de Agostinho Moreira dos Santos, de Joaquim da Silva (os Silvas de Évora), ou de Romão José Martins, entre muitas.

Paradoxalmente, na segunda metade de oitocentos, em Portugal, "os orçamentos domésticos, na sua maioria se equilibravam, quando não fechavam com superavit, enquanto o do Estado acusava deficit" (Peres 1935: VII, 383). Compreende-se a razão da quantidade de oferta de divertimentos populares, ainda que Ramalho Ortigão ou Fialho de Almeida Ihes encontrem pouca qualidade cultural. Mas é o espaço interclassista da feira franca que permite a afluência democrática aos espectáculos de Arlequins (pantomimas) de Joaquim da Costa Oliveira (1850); de funâmbulos como os Dallot (1863); de prestidigitadores como Manuel Sanches Lara (1866-8) ou Eliza Herrero (1868); de figuras de cera de Sebastião Malaganiga (1862-8), de Luís Cavana (1863), ou de Anna Doysk (1865); de teatros de marionetas, de Ellenberg e Marchand (Teatro Mecânico 1858-9), de Francisco da Costa (1864), de Frutuoso de Sousa ou de Francisco Aranda (1868); de aberrantes mulheres barbudas, de Casimiro Alsina e a "Cabeça Falante" (1868), de Antoine Giffray exibindo a filha "de 4 anos que pesa 140 quilogramas"2. Um caleidoscópio emocional, culminando em pirotecnia nocturna, ambiente de fortes cores musicais, por orquestras roufenhas interpretando polcas, mazurcas, e outras modinhas, como testemunha Júlio César Machado e a sua geração boémia.

\section{Os teatros-barraca das feiras francas}

Construções de madeira e lona, propriedade de, entre outros, o Araújo, o Vilar, ou o Palhares, em que o mais notável, opina Matos Serqueira, era o dos irmãos Dallot. Filhos de funâmbulos, Joseph, Charles e Julie, vieram actuar a Portugal por volta de 1845, escriturados no Circo de Madrid, dirigido por Paul Laribeau. São referenciados os "intermédios" de Mr. Dallot, de parceria com Mr. Ratel, em anúncios publicados no Diário do Governo, entre 15 de Março e 1 de Dezembro de 1845. Partiram para Espanha e Inglaterra, conquistando renome como ginastas e acrobatas, e, de regresso a Portugal, terão trabalhado na praça do Salitre, possivelmente para Hipólito Tournour (1858-1860), seguidamente na do Campo de Santa Ana, para Francisco Rodrigues Alegria, e, ainda, no Circo Price.

Encontramo-los definitivamente em Portugal, por conta própria, em 1863. A 9 de Outubro, Joseph Dallot requer a primeira licença "para dar espectáculos ginásticos em diversos theatros do Reino" ${ }^{\prime 3}$. Em 1868, o licenciamento

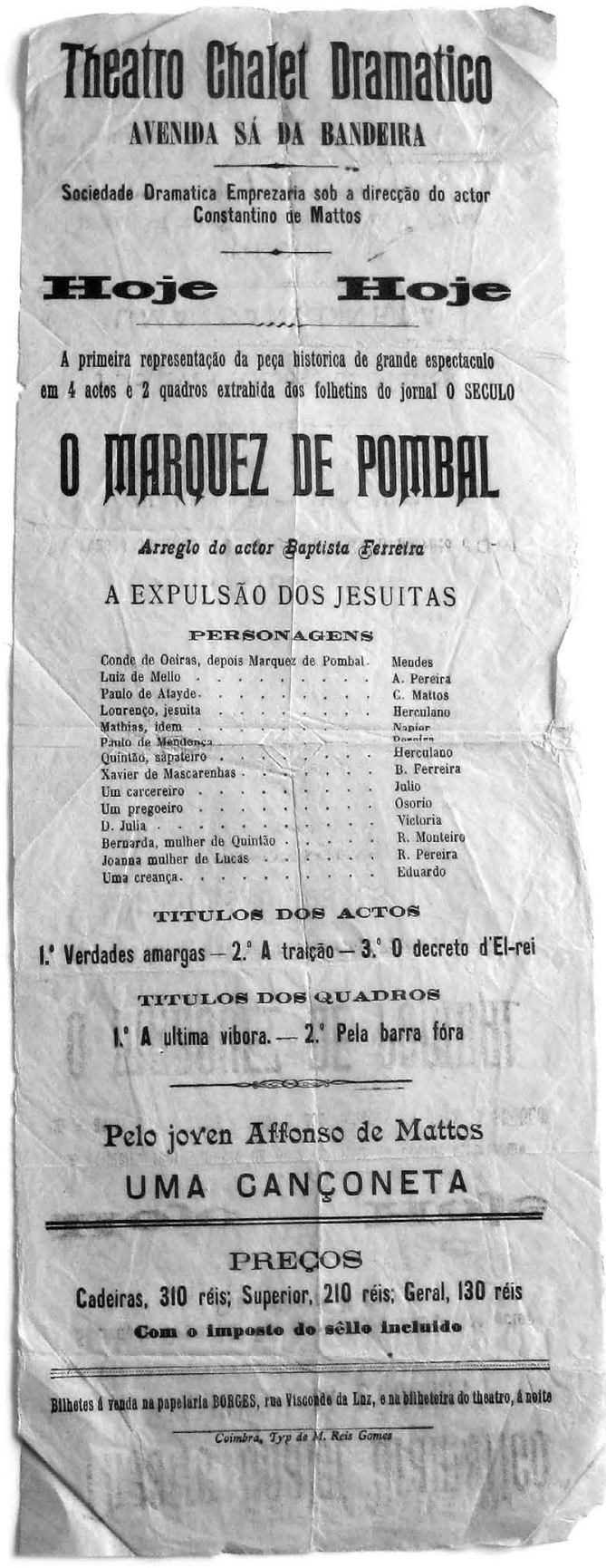

alarga-se a novas actividades, "pelo tempo de 6 meses, para dar espectáculos públicos de ginástica, teatro mecânico, física recreativa, cosmorama e outros próprios de circo, em diferentes terras do Reino" ${ }^{4}$. Por esta altura, os Dallot construíram o seu próprio teatro-barraca, deambulando por feiras e romarias, representando "comédias ingénuas entremeadas com as habilidades do célebre cavalo elástico (...) O Mosca e com as graçolas e as truanices do Joaquim Confeiteiro, que ficou célebre na personagem do Malhão, no Processo do Rasga, e que fo durante muito tempo o palhaço preferido do Teatro Infantil das Amoreiras" (Sequeira 1967: 251). Percorreram o país de norte a sul, deslocaram-se à Madeira e aos Açores, e foram a grande atracção feirante.

José Dallot - que falecerá, em 1906, em Santarém casou e teve uma filha, Estrela Dallot, que foi actriz em companhias ambulantes (a de Oliveira Tainha, e a 

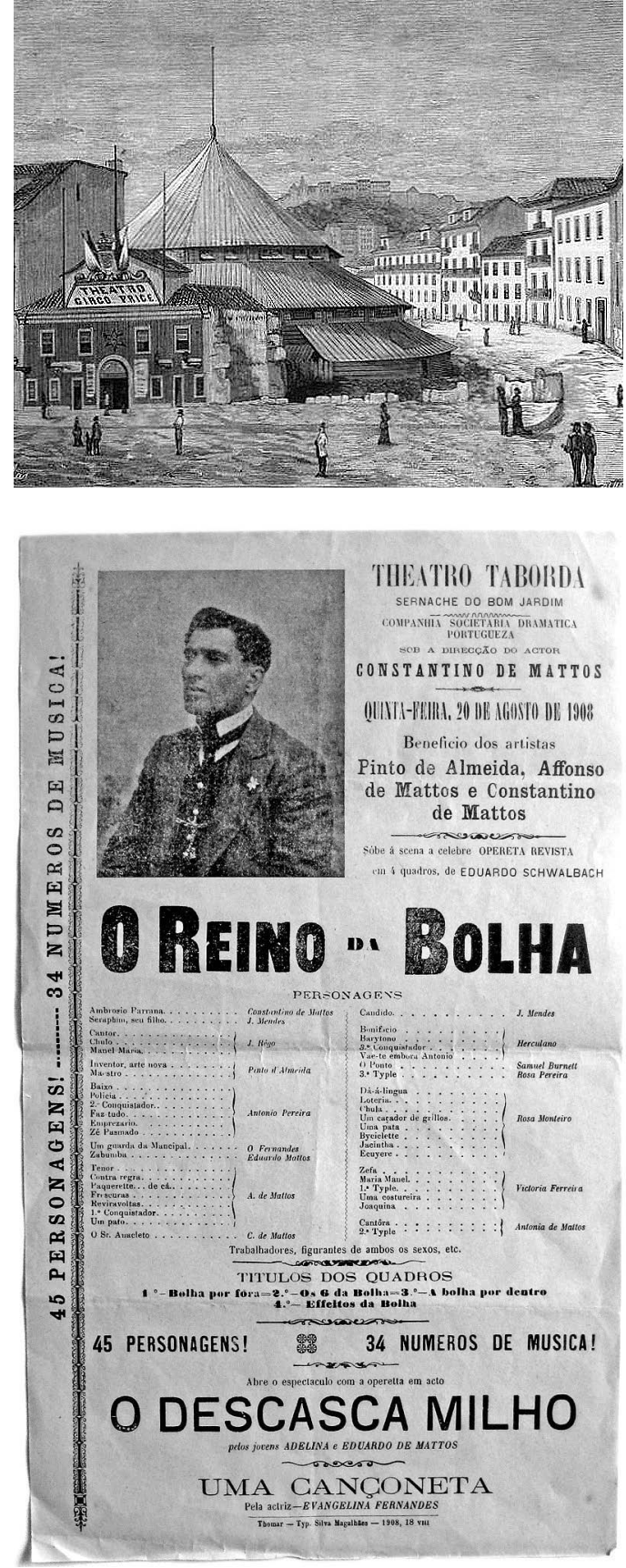

Companhia Dramática Aliança) e casou com o actor Roberto de Oliveira, filho de Julieta Rentini, directora da companhia do mesmo nome. Júlia Dallot casou também com um português; faleceu em Pedrouços, por volta de 1908, e a sua descendência foi dona de barracas de feiras. Carlos Dallot, mais ambicioso, terá sido empresário do teatro das Carmelitas, do Porto. Ganhou bastante dinheiro, mas apaixonou-se pela mulher de um sapateiro e decidiu fugir com ela. Situação rocambolesca! "Para se precaver contra as exigências de credores antigos, deposita em nome da transitória amante dez contos, que forrara. A divindade morre. 0 marido vinga-se ao abrigo da lei. Saboreia o lucrativo castigo da traição da cara-metade e do sedutor, recebendo, como legítimo herdeiro, os dez contos de Dallot" (Noronha 1919: 1). Em 1909, muito idoso, rodeado da numerosa família, explorava, no Dafundo, o Teatro Chalet Recreio Glória.

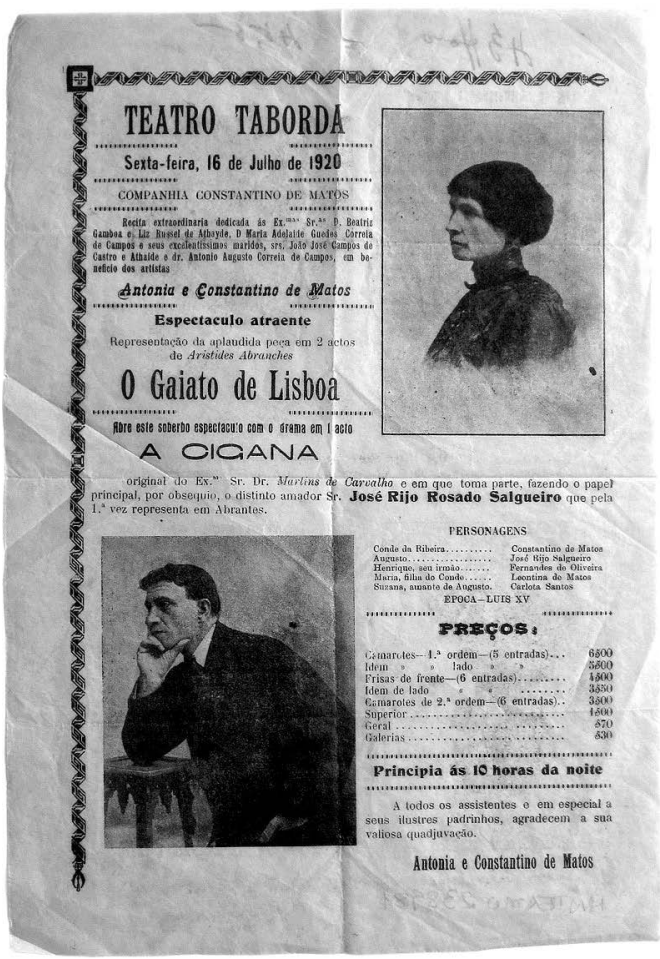

Teatro-Circo Price: vista exterior, desenho de D. Casellas (Ocidente, 1883-04-11, p. 85). Seria demolido para a abertura da Avenida da Liberdade.

Espectáculo de beneficio de Constantino de Matos e sua mulher, no Teatro Taborda, em Abrantes, em 16.07.1920.

A recordação desta família "de boa apresentação, chapéu de coco e sotaque francês" (Envia 1947) permaneceu por muito tempo na memória popular, servindo de modelo de comparação com outras farândolas. Diferentes periódicos regionais relevam o vasto reportório que exibiam em espectáculos variados. A tradição francesa dos teatros-barraca de arlequinadas e paródias burlescas desenvolveu, pela sua mão, uma escola de artes de espectáculo para actores ambulantes.

\section{Os "filhos" de Dallot}

Muitos nomes se poderão citar quando se catalogarem os que passaram por esta companhia nos cerca de quarenta anos que deambulou pelas províncias. Para já, ficam os que as fontes dispersas nos mostraram como seus seguidores:

Jaime Venâncio, actor, cenógrafo e autor, de cuja pena saiu uma famosa opereta, 0 processo do rasga, paródia ao Processo do Can-Can, que teve continuidade em 0 casamento do rasga; sua mulher, Elisa Aragonez, actriz que também fez êxito nos teatros populares de Lisboa, tendo representado no Teatro da Alegria, de Francisco Jacobetty, Torpeza, original de Campos Júnior, em resposta ao Ultimatum inglês. A sua descendência continuou em posteriores companhias de província: Lisbonense Venâncio (1920s), Conjunto Familiar Lisbonense "Os Venâncios" (de Leonel Venâncio, 1926-1960), Companhia Dramática Lisbonense "Les Moirons" (1930-60), Companhia Rentini (1930-1946), Companhia Lisbonense Venâncio "Os Modestos" (1943), Grupo de Teatro "Os Venâncios", Conjunto Nunes Vidal, Companhia Rafael de Oliveira, Artistas Associados (1960-75); Grupo Artístico Venâncio (de Aureleano Pereira Bragança Jr., 1960).

Henrique d'Oliveira (1865 - 1935), "filho do tão falado Joaquim José d'Oliveira que organizou a conhecida companhia de Oliveira Tainha, que foi um clown e um disciplinado director de companhias de circo e dramáticas".
Cartaz de 0 reina da bolha pela companhia de Constantino de Matos, no Teatro Taborda, em Cernache do Bom Jardim em 20.08.1908 
Actor Eduardo de Matos, filho de Constantino de Matos (Acervo Álvaro de Oliveira).

Cartaz publicitário da Companhia Dramática Lisbonense, dirigida por A. Cândido de Oliveira, para o Teatro Taborda, em Abrantes (data incerta).

Recorte jornalistico noticiando a Trupe 0 s Hernandos, em Ponte de Sor, em 14.06.1930. Trata-

se da familia Carmo e Muñoz. (Acervo de Eunice Muñoz).

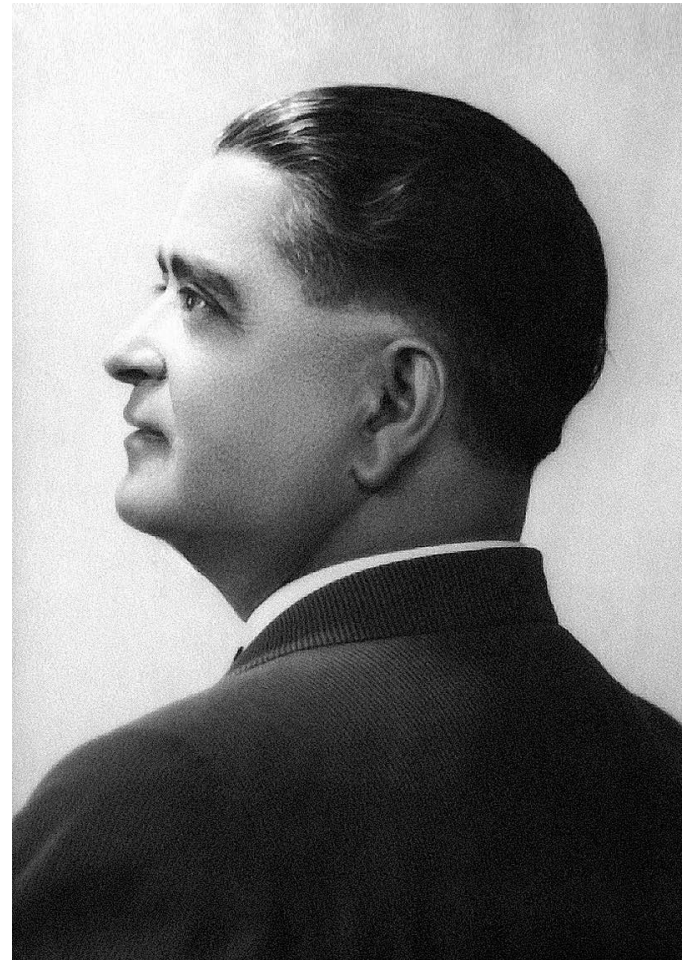

A descoberta dos "segredos da pista e do palco" principiou desde criança, na companhia infantil dos Dallot, onde "debutou e onde, por vontade do pai, alternava o trabalho, exibindo-se como acrobata e como artista dramático na mesma noite" (Dubini 1925: 1-2). Com gosto, aprendeu música, ganhou recursos e tornou-se num elemento de grande valor em qualquer grupo. Na Companhia Tainha conheceu Isabel, neta dos empresários, de quem teve descendência ligada ao espectáculo: a actriz Auzenda de Oliveira, vedeta de operetas e zarzuelas em 1920.

Constantino de Matos, que aos 14 fugiu de casa, na companhia ginasta dos Louradores, estreou-se na companhia dos Dallot, na feira do Campo Grande, n' 0 processo do rasga. Representou as peças do reportório feirante, desenvolveu qualidades artísticas e fez-se actor. Quando deixou os Dallot, formou a Companhia Dramática Societária, o agrupamento mais bem organizado do seu tempo, dizia-se. Possuiu um Teatro-Chalet - onde Ângela Pinto chegou a representar (Câmara 1906: 81) -, por pouco tempo. Um incêndio destruiu-o, em Estremoz, em 1913. 0 temperamento de lutador fê-lo continuar, com o apoio da família teatral que constituíra, das filhas Leontina e Adelina de Matos e dos filhos Eduardo e Afonso de Matos. 0 casamento das filhas e a partida dos filhos para os teatros da capital levaram a que, cansado, Constantino de Matos deixasse a vida itinerante e se tornasse comerciante em Castelo Branco.

Domingos Cândido da Silva, o sempre jovial - "a mocidade nele era perpétua" ${ }^{5}$-, foi um cómico apreciado em toda a provincia, e considerado o melhor dos escudeiros das mágicas; fora o "Mirundela" d' 0 processo do rasga, na companhia de José Dallot, na feira do Campo Grande em Lisboa. Inicialmente de sociedade com Santos Carvalho, formou a Companhia do Teatro Lisbonense, que durante 12 anos percorreu o país, representando no seu próprio teatro-barraca, que construia de cada vez que assentava arraiais. As referências ao Teatro Lisbonense remontam
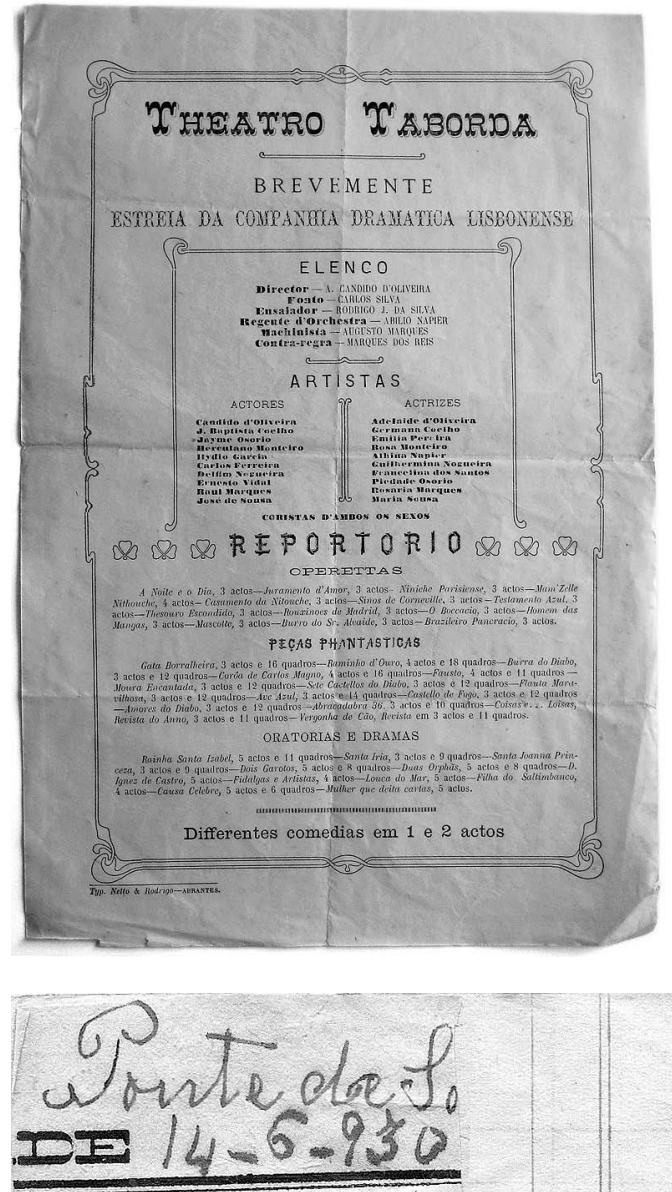

\section{A luz da ribalia}

Realisou-se ontem no Cinema Heal, un espectaculo dramatico levado a tíito pela troupe OS HER NANDUS, da qual fazem parte as artistas Augusta Carmo. Mimi Murihóz, Aurita e Oeorgete Carmo e os actores F. Carmo, Hernaui Munhoz e José do Carmo. Subirain á scena o drama em 2 sctos,

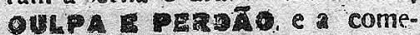
it M14. a

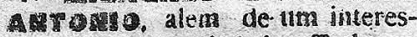
sante actu de variedades. Todos os ar tistas se houveram di altura dos seus pap-is, pelo que receberan fartos aplausos.

Pena foi que o publico nåo ti vesse proporcionado a Os Her. nandos uma bua enchente, coro. ando de exito o trabaltho conscien. cio-o destes artistas. Vai certamente proporcionar llua na proxim quinta-feira, dia em que se realis quinta-feira, dia em que se realis.
a segundo e ultimo espectacul.

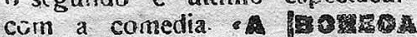

aLguñ. e outros interessante

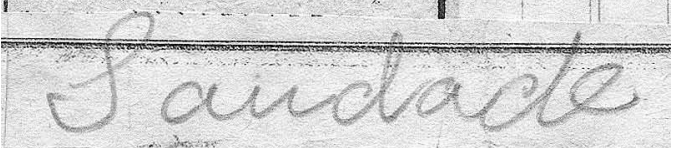

à última década de oitocentos, acompanhando o movimento das feiras.

Em 1906, o actor Domingos funda 0 actor errante, pequeno e modesto periódico, subintitulado "quinzenário cosmopolita", em que se abordam assuntos diversos, 


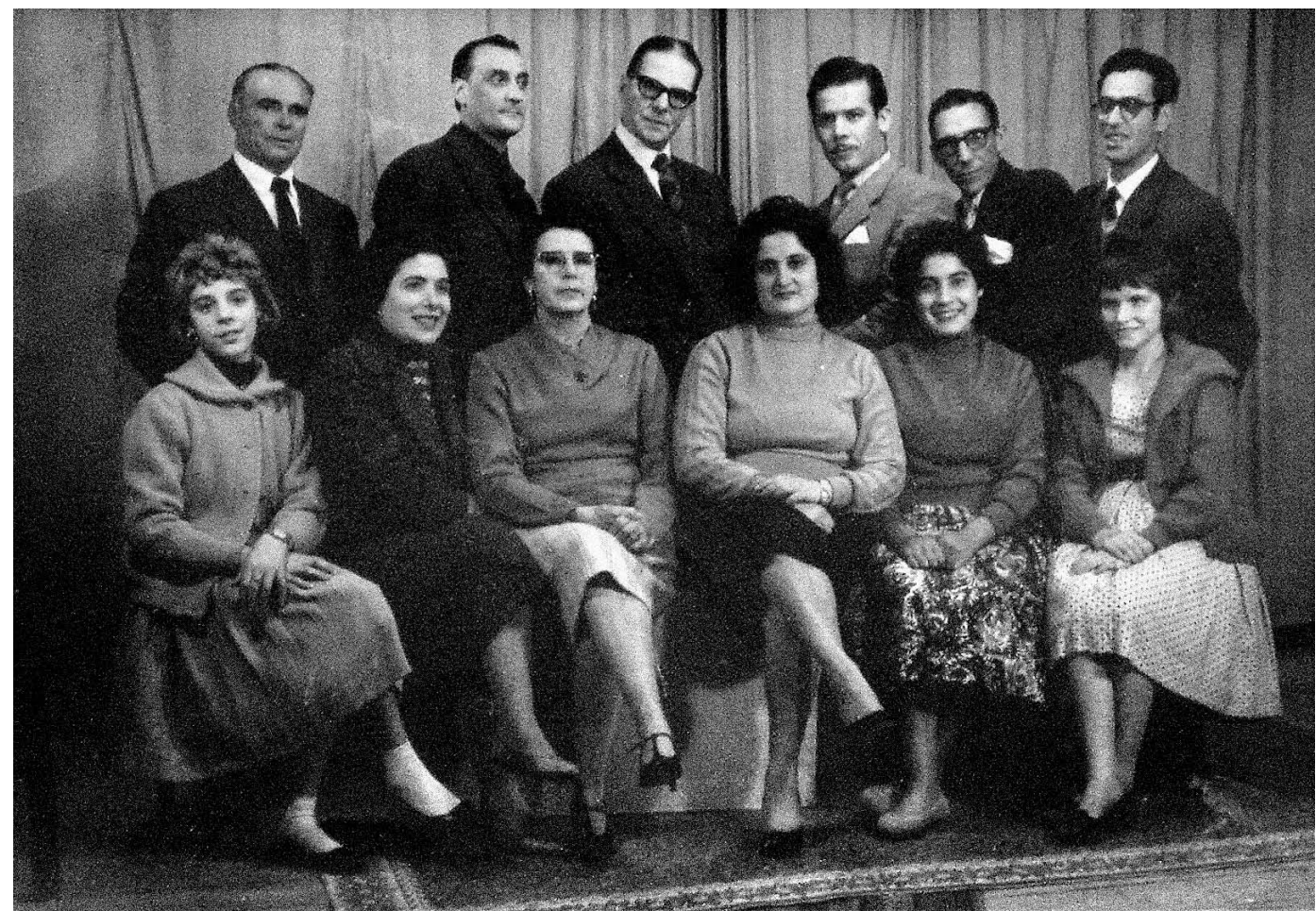

Foto da Companhia Moiron, c. 1950, tirada no palco do Teatro Desmontável Moiron Sentadas: Fátima Moiron Felisbela de Andrade, Anita Moiron, Mary Custódia, Maria Teresa de Andrade, Armanda Moiron. Em pé: Emílio Moiron Humberto de Andrade, Paulo Moiron, Armando Venâncio, Artur Caldas, Ponto [nome desconhecido] (Acervo de Armando Venâncio)

destinados a um público ecléctico de assinantes. Foi o "jornal dos errantes, daqueles que se arrastam de cidade em cidade, trabalhando sempre para poderem viver modestamente e com honra! É nele que nós distraímos o nosso espírito, é nele que publicamos as nossas impressões e que descrevemos a nossa vida de teatro" ${ }^{6}$. Um periódico próprio de companhia de província parece-nos novidade e caso interessante no panorama português. Conhecemos os que abordam o espectáculo, jornais de especialidade, edições para artistas profissionais ou amadores, mas especificamente feito por actores itinerantes, ele próprio também itinerante, e de pretensões nacionais, afigurase-nos caso único.

Com a dissolução da companhia em 1913, o actor Domingos recusa ser escriturado em teatros fixos; nem mesmo Afonso Taveira o demove. 0 gosto pela vida errante fê-lo preferir a proposta de Constantino de Matos, com quem fica até 1918. A morte pôs fim a 40 anos de glórias e contrariedades, de felicidade e desânimo, numa vida ambulante cansativa e desgastante.

\section{Aventuras e desventuras de uma companhia de provincia}

Grosso modo, a gestão empresarial dos itinerantes baseiase na estrutura familiar ${ }^{7}$. Em relação às companhias de província, essa estrutura psicossocial fundamenta a interligação entre a vida profissional e a social dos seus componentes. A coesão do agrupamento é um factor de sucesso público; cada componente contribui para o bem comum, exibindo o seu talento em palco, e coadjuvando nas tarefas rotineiras de bastidores: tanto se "passam" os papéis, como os fatos e os cenários. Agrupamentos unifamiliares ou plurifamiliares, as companhias organizamse em sociedades artísticas ${ }^{8}$. As receitas provêm dos espectáculos realizados, condicionando os societários espécie de cruzamento genético de cigarra e formiga lafontainiana -, a uma vida "de judeu errante", pasto do anedotário de autores e actores memorialistas e de outras inventivas rocambolescas.

As companhias possuíam cenários próprios, segundo as peças representadas. 0 enquadramento cenográfico possuia a importância da assinatura de um cenógrafo (ainda que de modesta extracção). Graças à tipificação da iconografia cénica, as "vistas" podiam ser reutilizadas em outros enredos, concordando com o ambiente requerido. Era conveniente possuir vistas de sala,- burguesa ou nobre-, de cárcere, de praça pública, de bosque, de mar, e de tudo o mais que o investimento pudesse pagar. Igual princípio se aplicava ao figurino, propriedade de cada artista, o qual se compunha de peças basilares, consoante as tipologias interpretadas. Tal permitia uma multiutilização em espectáculo, segundo um padrão de bom senso e de bom gosto, consoante os critérios de propriedade, definidos pelo ensaiador ou director de cena.

Vestir com graça, com naturalidade e com bom gosto é qualidade fundamental do actor, o que quer que represente. Meio caminho andado para a vista do espectador, "o actor e a actriz precisam tornar-se modelos, porque estão à luz da ribalta, durante muito tempo, em exposição perante um público inteiro, onde há muitos artistas e muitas pessoas de bom gosto" (Bastos 1994: 154). Qualquer societário possuía guarda-roupa base, de uso formal ou quotidiano, e sapataria a condizer. Casaca, sobrecasaca ou fato completo, equivaleria a vestir um conjunto de personagens masculinas de "actualidade", desde o jovem galã ao pai de família; o guarda-roupa das actrizes incluía espécies segundo o seu "naipe". As pupilas do senhor Reitor, como as Rosas do Adro, e outras figuras de zarzuelas importadas, aformoseavam-se no colorido das mondadeiras minhotas ${ }^{9}$. Burguesas em tafetá, aristocracia em veludo, e, para vestir semanticamente a "ingénua", bastava um vaporoso vestido claro. Os apêndices capilares provêm de cabeleireiros alugadores de postiços,
${ }^{6}$ Oactor errante, Ano 3. n. ${ }^{\circ} 56$, Edição de Guimarães, 08.11.1908: 1

Muitos actores casam entre si, ou vivem uniões de facto. As empresas artisticas afiguram-se prolongamentos dos consórcios matrimoniais, criando um património comum. Maria Matos Mendonça de Carvalho Rey Colaço - Robles

Monteiro, Brunilde Júdice - Alves da Costa, entre tantas, são exemplo de estruturas empresariais familiares que praticaram itinerância artística.

\section{" "Artisticas", por se}

tratarem de associações de profissionais, ou "da arte".

${ }^{9}$ A zarzuela original de Carlos Arniches e Asencio Más, Un puñao de rosas, teve imitação de João Soller, com o titulo de Rosas de Nossa Senhora de aragonesa acomodouse minhota. 
Capa do Livro de Contas

da Companhia de

Rafael de Oliveira

(Companhia de provincia), de 1945 (Acervo Álvaro

de Oliveira).

Afonso de Matos,

filho de Constantino de

Matos. Foto oferecida a

Rafael de Oliveira, na noite da sua Festa Artistica, em

30.03.1933. Um gesto

tradicional de amizade praticado entre actores de então (Acervo Álvaro de Oliveira).

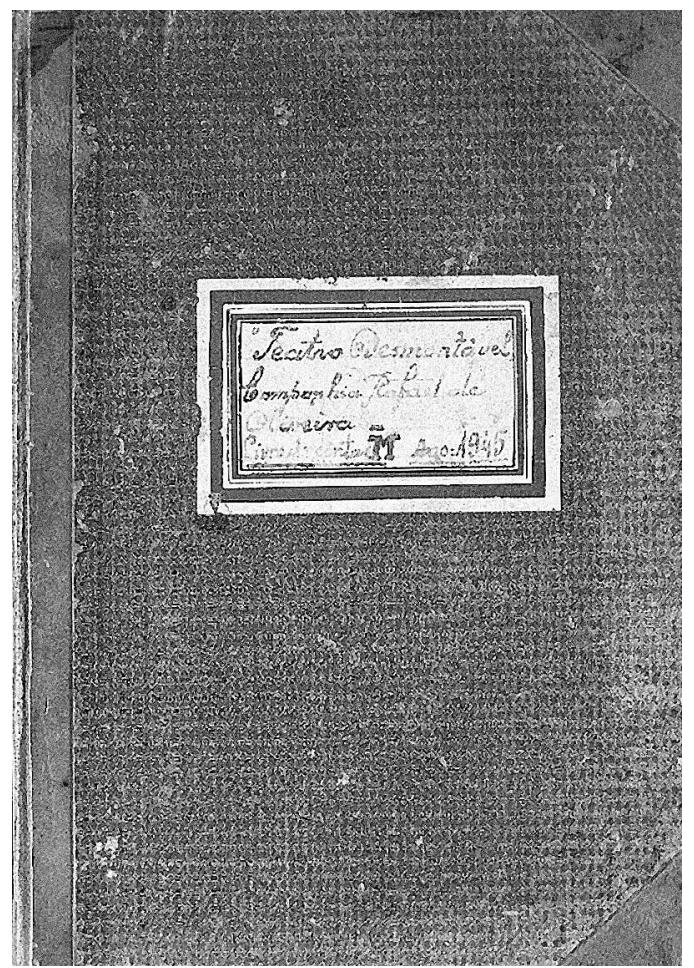

em que sobressai a Casa Vitor Manuel, de Lisboa. Perucas, barbas e postiços são tropos da psicologia dos papéis: a sageza das cãs do ancião, o bigode façanhudo do fanfarrão, as volumosas patilhas de regedores e outros rurais, ou a finura negra do bigode que delineia o lábio do cínico, e define o esgar predador de ingénuas órfãs desvalidas. Códigos que o tempo apagou.

A tradição familiar desenvolve a transmissão interpretativa, herdando os jovens actores, não só os "papéis", como o respectivo figurino, quando o real envelhecimento do primitivo intérprete obste ao desempenho de tipos desenrugados. Nestas companhias, o vedetismo não tem cabimento, mas manifestam-se crises de personalidade; o espaço emocional da vida errante aumenta a sua intensidade. A passagem de testemunho era a evolução natural, correspondia ao lema "filho és, actor serás". Os jovens galãs transformavam-se em centrais, até que a idade Ihes conferisse o estatuto de pater familias, assim como as ingénuas evoluiam em damas centrais e aposentavam-se em velhas matriarcas.

Para um actor de província, vida social e a profissiona são uma e a mesma coisa. Antecedendo a instalação da companhia, já o director estabelecera contactos com as autarquias para licenciamento do recinto e construção do teatro-barraca. Quando o grupo se deslocava com "armas e bagagens", procedia-se à ocupação das casas alugadas, conforme a necessidade das famílias societárias, que as mobilavam com objectos pessoais, transportados em conjunto com os pertences teatrais. Em seguida, o director da companhia efectuava visita de cortesia pelas redacções locais, sugerindo, a troco de um lugar cativo de plateia, o apoio jornalístico na divulgação de um reportório pensado, diziam, para um público merecedor de toda a consideração e estima de quem Ihe dedicava o modesto labor de divulgador da Arte de Representar. A primeira abordagem promocional antecedia o contacto com empresários locais (teatros, agremiações, casinos, cafés-

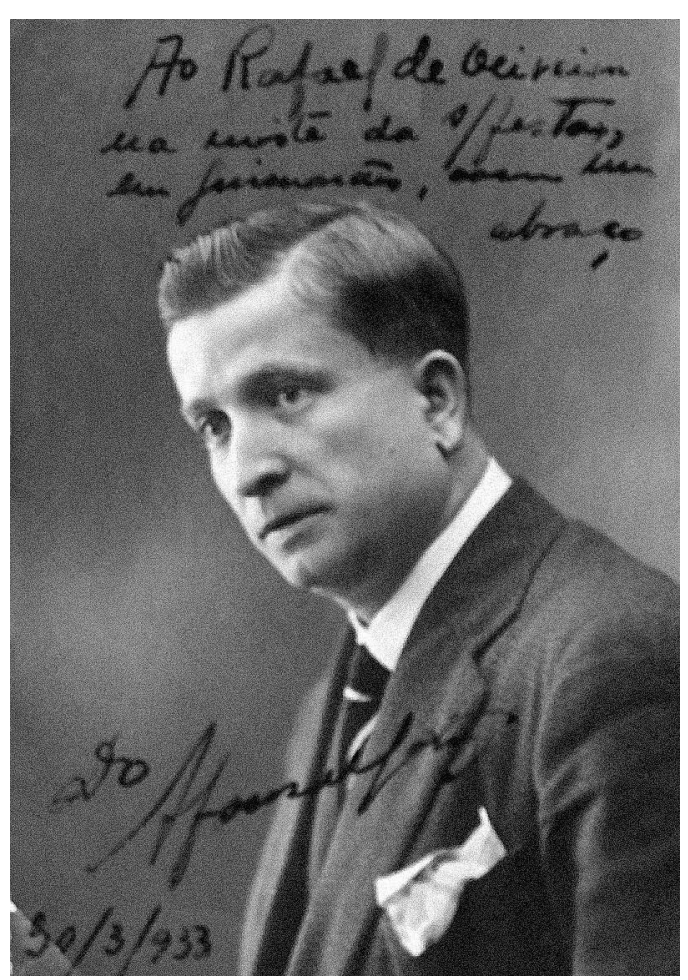

concerto), potenciais contratadores de espectáculos suplementares, complemento do calendário, além das terças, quintas e sábados, tradicionais dias de representação.

Enquanto isso, o elenco fazia o passacalle, prolongado passeio pelo Rossio, espaço de confluência do públicoalvo. "Já cá estão os cómicos!", ouvia-se. A companhia distribuía sorrisos, cumprimentos, entabulava conversa; trocavam-se reciprocas saudades de anteriores visitas, expressava-se o desejo de voltar a deliciar quem sempre tão bem os recebera. Fórmulas simples de prospecção de público. E o contacto prolongava-se na impressão de "programas" e bilhetes em gráficas locais, na sua colocação no comércio de maior afluência - barbearia, mercearia, botequim -, antepassados das contemporâneas ticket lines. Garantia-se assim o bom acolhimento, o sucesso da temporada, e, no entrosamento quotidiano, fomentavamse laços afectivos de saudades prospectivas de regresso.

A estadia dependia do licenciamento camarário periodos de três meses, com possivel renovação - e da afluência de público. 0 sustento de todos advinha da quantidade e qualidade do reportório, variado, e do gosto popular; exigindo, portanto, uma carteira de espectáculos tocando diferentes inteligências emocionais, e valorizando os dotes artísticos dos seus intérpretes. Ainda que houvesse cortes textuais, ou se desdobrassem personagens, as "peças de grande espectáculo" exigiam um elenco adicional de figurantes e pequenos papéis, recrutados entre os amadores locais, conhecedores praticantes desse reportório, levado à cena nas colectividades. Actores "diletantes" e "da arte" criavam laços artísticos: constituiam grupos de amadores dinamizavam a sua formação técnica e contribuiam para a literacia do público. É manifesta a postura crítica, tantas vezes exacerbada, sempre que uma companhia profissional visitante não cumprisse os requisitos essenciais, quando os seus amadores os haviam já superado. Curiosidades bairristas tornadas públicas pelos Buritys de provincia na imprensa local! 

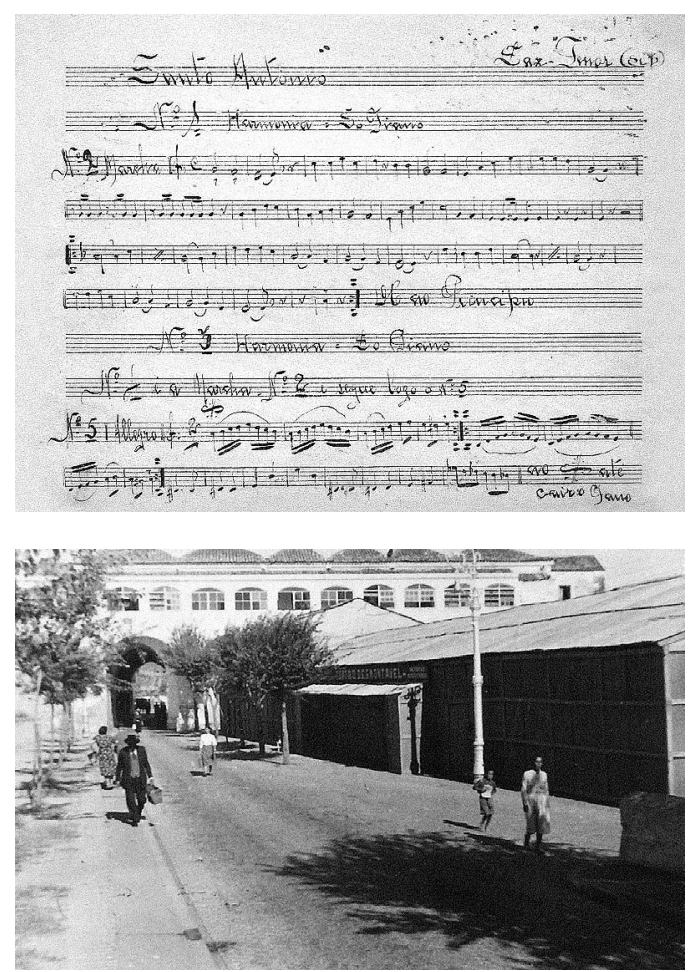

A qualidade da vivência social destes forasteiros dramáticos, indo à missa, levando os filhos à escola, auxiliando as instituições de solidariedade, conferia-Ihes, à luz do dia, o estatuto de amigos queridos, que sob a luz da representação sofria a transfiguração própria da arte de Talma. Eis o fascínio deste teatro popular! E qualquer "cabo de companhia" conhecia as regras de mercado, especificamente diferentes das praticadas pelas companhias de itinerância pontual de fim de temporada urbana. As feiras e o veraneio eram propícios ao reportório ligeiro, do agrado do ruidoso público da geral. Para ele, se exibiam mágicas e operetas, comédias, farsas e finais de espectáculo ao estilo Folies Bergère, pomposa designação para simples variedades: monólogos chistosos, cançonetas melodicamente atractivas, de líricas brejeiras, com vislumbres de tornozelos e decotes ousados. Mas era com o frio do Inverno, que apeteciam os dramas pungentes e as novidades, entretanto ensaiadas: conflitos humanos de fácil identificação, um teatro sentido, de vidas sofridas, um teatro convidando os "amantes da arte" a fruirem um espaço comunitário de exibição do gosto artístico e do desejo de prestígio local.

Entre a cidade e as serras, numa visão pretensamente cosmopolita e elucidada, a crítica lastimava que subissem à cena dramas passadiços, sem interesse educativo, mas reconhecia inevitavelmente que a modernidade teatral não atraia o sentir da população rural, condicionando as companhias aos mesmos temas por sobrevivência. 0 teatro era uma "indústria", levada com rigor e convicção de bom senso, sem estéticas de gosto requintado, um luxo para intelectuais. Os melodramas de importação francesa, e os de criação nacional, eram acolhidos com desvelo; adaptações folhetinescas, lidas e ouvidas, sofriam-se na compaixão de quem se reconhece nas agruras de amores propícios, de gaiatos traquinas, órfãs e ceguinhas, ou nos funestos, de Teresas de Albuquerque, de Rosas do Adro ou de outras sofredoras. 0 júbilo chegava com as comédias de costumes, com a magia das oratórias, com as feeries dos velhos tempos das mágicas do Salitre, do Ginásio, das operetas do Trindade, dos vaudevilles e melodramas do Apolo e mais as ingénuas revistas de produção regional. Uma literatura popular, publicada por livreiros e editores, constituindo "bibliotecas dramáticas populares" e colecções de "teatro escolhido", reportórios acessiveis para "salas e teatros particulares", destinado a "artistas e amadores", com garantia de "gerais aplausos" e "agrado certo". E o público acorria a comprar o bilhete, consoante a possibilidade e o interesse pelo enredo, ávido de compartilhar os dramas de honra dos seus pares serralheiros, marinheiros, gente de labor proletário, paradigmas de um sonho democrático de liberdade, confluências de anarquistas, socialistas e republicanos, uma sociedade desenvolvida a partir da regeneração liberal, que acreditava no valor do trabalho, no dever de cidadania e no progresso pela educação. E, no fim, aplaudia sonoramente a "ingénua" e apupava com dobrada veemência o "vilão": era o delírio da geral, dos sempre vibrantes Enfants du Paradis.

0 que motivava estas gentes do teatro a sentirem prazer nesta vida errante, de vicissitudes óbvias? Amor incondicional pela Arte de Talma, transmitida pela tradição geracional? Desejo de uma vida de liberdade, que a cidade Ihes coarctava, impondo-Ihes uma concorrência mesquinha e uma diminuição do espaço de actuação? Adelina Abranches confessa-se: "Meti-me em comboios abjectos, que me deixavam tão mascarrada como qualquer limpachaminés. Conheci o prazer das grandes ovações e o travo das pequeninas insídias. Mas deixá-lo. Diverti-me. Que de recordações trouxe dessa minha primeira 'escapada' por terras das nossas províncias! Que motivos de beleza surpreendi em muitas voltas de estrada! Beleza, que eu estava longe de sonhar que existisse por todo esse Portugal fora!" (Abranches 1947: 84).

\section{Referências bibliográficas}

ABRANCHES, Adelina (1947), Memórias de Adelina Abranches: Apresentadas por Aura Abranches, Lisboa: Edição da Empresa Nacional de Publicidade.

BASTOS, Sousa (1994), Diccionário do Theatro Portuguez (1908), Lisboa, Editorial Minerva, edição fac-similada.

CÂMARA, D. João da (1902), "A Farandula", Revista do Conservatório Real de Lisboa, n. 1 .

-- (1906), Ângela Pinto: Esboços, homenagens e apreciações criticas. DUBINI, Carlos (1925), "Gente de Teatro", Jornal dos teatros, 06.09.1925: $1-2$.

ENVIA, Manuel (1947), Coisas de Setúbal: Prosas regionais, s.l., s.n. (Setúbal: Tip. Simões).

NORONHA, Eduardo de (1919), "Folhetim, Teatro, Barracas de Feira", Diário de noticias, 21.10.1919: 1

PERES, Damião (dir.) (1935), História de Portugal. Edição monumental, Porto, Vol. 7.

\section{Gabriel e Lusbel ou a Vida do Taumaturgo, oratória de Braz Martins, com música de Ângelo Frondoni. Partitura manuscrita pertencente ao espólio da Companhia} Rafael de Oliveira.

Teatro desmontável da Companhia de Rafael de Oliveira (c. 1950, local desconhecido). 


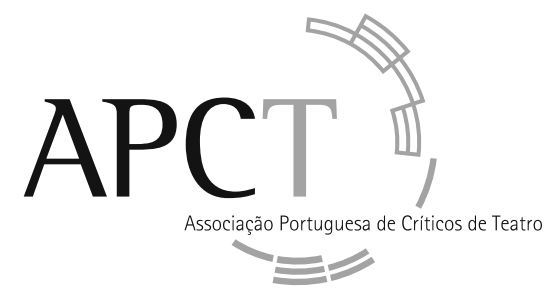

\begin{tabular}{c|l} 
Presidente honorário & Luiz Francisco Rebello \\
Direcção & $\begin{array}{l}\text { Maria Helena Serôdio } \\
\text { João Carneiro } \\
\text { Rui Pina Coelho }\end{array}$ \\
Assembleia Geral & $\begin{array}{l}\text { Paulo Eduardo Carvalho } \\
\text { Sebastiana Fadda }\end{array}$ \\
Conselho Fiscal & $\begin{array}{l}\text { Ana Isabel Vasconcelos } \\
\text { Mónica Guerreiro } \\
\text { Rita Martins }\end{array}$
\end{tabular}

ESTATUTOS $\quad$ Capitulo Primeiro (Da Associação e dos seus fins)

Art. ${ }^{2} .^{\circ}$

A Associação tem por objectivo:

Dignificar, estruturar e responsabilizar a actividade crítica relativa à teoria e prática do teatro, entendendo-se por actividade crítica não só a crítica de espectáculos, mas também tudo aquilo que diga respeito à informação, reflexão e teorização no campo das artes performativas.

\section{Colaboração com Sinais de cena}

A revista está aberta à participação de quem deseje colaborar enviando artigos que julgue corresponderem aos objectivos da publicação e às modalidades enunciadas pelas rubricas existentes. A consulta do sítio da APCT na Internet (www.apcteatro.org) e o contacto por correio electrónico (estudos.teatro@fl.ul.pt) são indispensáveis para conhecer as normas de apresentação dos artigos (dimensão, aspecto gráfico, citações, referências bibliográficas, ilustrações, etc.).

\section{ASSINATURA}

Desejo subscrever os números 13 e 14 da revista Sinais de cena (correspondentes a Junho e Dezembro de 2010), no valor total de $22,00 €$ beneficiando assim de um desconto sobre o preço de venda ao público. Fora do pais: Europa $24,00 €$ / Fora da Europa $26,00 €$.

Nome:

Morada:

\begin{tabular}{l|l} 
Código postal: & Pais:
\end{tabular}

Endereço electrónico:

Forma de pagamento:

Vale postal

Cheque $n^{\circ}$.

Banco

(passar à ordem de Associação Portuguesa de Críticos de Teatro)

Preencha e envie este cupão (ou fotocópia do mesmo) para:

Data:

Sinais de cena

Centro de Estudos de Teatro

Faculdade de Letras de Lisboa: sala 67

Alameda da Universidade

1600-214 Lisboa (Portugal) 